\title{
Application of Elasticity Theory for Assessment of Social and Economic System Sustainability
}

\author{
Galina P. Litvintseva \\ Department of Economic Theory and Applied Economics \\ Novosibirsk State Technical University \\ Novosibirsk, Russia \\ litvintseva-g@mail.ru
}

\author{
Alexey I. Karpovich \\ Department of Economic Theory and Applied Economics \\ Novosibirsk State Technical University \\ Novosibirsk, Russia
}

\begin{abstract}
The source of emergence of sustainability problems related to social and economic systems lies in factors of complexity and uncertainty. The presence of sufficient sustainability in the performance of social and economic objects characterizes effectiveness of adaptation mechanisms and their abilities in risks overcoming. In our opinion, sustainability assessment is possible on the basis of the theory of elasticity connected to adaptation potential formation. The article proposes and tests authors' approach to social and economic systems sustainability assessment. The used criteria were as follows: functionals of difference or relation between real and ideal characteristics of system performance quality. To estimate connection between resource perturbations and deviations from program reference points of system development the elasticity functions were elaborated. They are derived by correspondent modification of production functions. Recommendations for ways of perfecting the mechanisms running programs of social and economic systems development on different levels are proposed.
\end{abstract}

Keywords: socio-economic system, sustainability, elasticity function, resource disturbances, regional project

\section{INTRODUCTION}

Establishing of sustainable economic development of states national economies basing on a set of principles such as quality of life improvement, rationalization of output and consumption structure, ecosystems preservation and so on, is especially actual in the conditions of economy which is in growing extent based on knowledge, innovations and digital environment development.

The concept of sustainability is most widely used in various fields of science and engineering where sustainabilities of elastic systems and fluid motion as well as sustainabilities of structures, automatic control systems, transport vehicles, electric power systems, thermodynamic stability, etc. are studied. Their definitions are based on the mathematical theory of stability where the latter is characterized as a term which does not have any clearly defined meaning and is applied to motion, to geometric or any other objects depending on parameters, e.g. statistics (statistical stability). However, it is emphasized that the above application fields of the term 'sustainability' do not fully cover its essence [1].

Among various concepts of motion stability the most popular are S. Poisson's, G. Lagrange's, A.A. Andronov's and L.S. Pontryagin's definitions as well as A.M. Lyapunov's concept of stability. In analyzing sustainabilities of various systems concepts of local (in small) and global (in large) stabilities are of great importance [2].

A system is locally sustainable if the stability property is defined only for states sufficiently close in some appropriate sense to the initial state (or for trajectories lying "near" the initial trajectory). A system is globally sustainable if the stability property is applied to all states (trajectories) within the domain in which the system is studied.

In our opinion, the obvious variety of definitions of stability includes some general feature that characterizes the essence of this category, namely, its idea of some object as an attribute of a given object to preserve (possibly with some deformations) its certain qualities, attributes or characteristics under uncertain conditions of its existence. According to this understanding equilibrium and homeostasis are a particular case of a stable state. In addition, viability can also be treated as a demonstration of the stability property of autonomous systems.

Therefore, the great importance is in economic tools of stability research including cost-benefit analysis, methods of assessment in conditions of uncertainty and risk as well as methods of assessment of economic policy tools impact on economic system sustainability [3]

\section{LITERATURE REVIEW}

In the economic literature the term "sustainability" is quite relative and allows various interpretations depending on the combination with various economic objects or categories such as market sustainability, economic sustainability in general, sustainability of development and economic growth, 
technological sustainability, financial sustainability, sustainability of money circulation, price, resource and ecological sustainability as well as some others.

The reported study was funded by the Russian Foundation for Basic Research (RFBR) according to the research project № 19-010-00195 “The impact of digital transformation of economy on quality of life of the population and public policy on decrease in its negative consequences in the Russian Federation".

The classic equilibrium interpretation of economic sustainability is most widely used in the social and general economic literature; it is formulated as follows: "when social and economic parameters characterizing an economic entity keep an economic equilibrium state at any level under any internal and external environment perturbations" [4]. However, we can and must speak about state sustainability as well as about development and functioning trajectory of an economic entity irrespectively of the fact if they are in equilibrium or not.

Modern economic systems (firms, organizations, regional and national economy) are complex systems with a goaloriented behavior, so not only organization but also selforganization are inherent to them in full extent. The matters of sustainability are especially important for them.

The term sustainable development appeared in the last third of the 20th century. It means a process of economic and social change in which the use of natural resources, the direction of investment, technological progress and institutional changes are coordinated and strengthen national capacity to meet the needs of the present generation, without compromising the ability of future generations to meet their needs [5]. In other words, a joint development (coevolution) that does not contradict the further existence and development of mankind. A need to ensure harmony in economic, social, engineering and natural components is declared in sustainable development agenda of the Organization of United Nations [6].

There are plenty of works on sustainability. Not claiming it to be an all-inclusive survey we would like to mention for purposes of our research that some of them devoted to global and national sustainability [7, 8], while others with sustainability in industrial complexes and organizations $[9,10]$ as well as sustainability in innovative economy [11] and environmental sustainability [12, 13].

In modern conditions the situation is notably changing. Digital transformation means implementation of digital technologies and business into economy, creating ecosystems on the basis of digital platforms, alteration of people's quality of life etc. Three main problems are remaining: employment, trust in conditions of sharing processes and sustainability. The report of the World Economic Forum notes that "current business practices will contribute to a global gap of 8 billion tons between the supply of and demand for natural resources by 2030 , translating to $\$ 4.5$ trillion of lost economic growth" [14].

In this regard it appears to be actual to research not only

The reported study was funded by the Russian Foundation for Basic Research (RFBR) according to the research project № 19-010-00195 “The impact of digital transformation of economy on quality of life of the population and public policy on decrease in its negative consequences in the Russian Federation". factors of systems economic sustainability, but also methods of its assessment in order to define in proper time deviations of target indicators from possible resource perturbations in ongoing transformation processes.

For this purpose in this research it is offered to develop the theory of elasticity connected with mathematical modeling of economic systems. As mathematical models it is expedient to use production functions, interest in which does not weaken. Really, production functions are applied in the modern analysis to assessment of effective functioning of companies [15], factors of economic growth of the countries of OECD [16], influence of a physical and human capital in various regions [17], changes of total factor productivity and its components in the countries of the world [18]. However, the author's approach provides not only the development and use of production functions, but also their transformation into other functions, which we called elasticity functions.

\section{MAin Conceptual Statements}

By economic sustainability of social and economic systems we would mean their ability to ensure fulfillment of their target indicators in uncertain conditions of functioning or development (for example, fluctuations of marker conjuncture, unpredictability of partners behavior, industrial technologic malfunctions, unreliability of resource suppliers and other possible perturbations). Such aspects of sustainability as resource, technological, pricing, financial and investment reflect manifestation of sustainability attribute towards either individual parameters or some fields of economy - output, consumption, logistics, finances and so on. We do not equate stability with sustainability, as the former could be considered as a special case of the latter's manifestation.

Economic sustainability can be classified into structural and functional-parametric ones.

Structural sustainability is an ability of a system as a community of economic subjects to self-preservation and selfreproduction as well as to maintain its integrity, organizational unity given different interests of the subjects involved in the system. It suggests the preservation of structural integrity as a set of certain necessary subset of interrelations of independent component parts defining the given system. Structural sustainability is actually a necessary condition for ensuring economic sustainability of this system and embodiment of its structural aspect. In fact, if target indicators of the system are achieved, it may be said at least that it retains its integrity. However, if a system is disintegrating (decomposing), the matter of its target indicators achievement is discarded at all.

Functional-parametric sustainability is subdivided into sustainability to small perturbations (sustainability in small) and sustainability to large deep perturbations which is formed due to managing ability and adaptability. Sustainability in small means that small changes in development conditions (functioning) of an economic object result in small deviations of actual values of its target indicators from the planned (program) ones.

Managing ability is a property (capability) of a system to generate rational managerial decisions (within the managing subsystem) and to respond adequately to managing actions. 
springs providing elasticity). Under otherwise equal conditions volume of losses characterizes elasticity degree as well, as it is the higher the lower losses are and controversially. The latter are a sort of "payment" for uncertainty used in information management. The attribute of elasticity is directly adjacent to risk-sustainability, as the latter is defined through elasticity and level of possible perturbations correspondent to evaluated variant of development / performance of social and economic system.

Elasticity of some object with a given program of its development or performance can be described with elasticity function approximating relation between input perturbations and deviations from planned (programmed) reference points. In this context elasticity determination and measuring appears as a mirrored transferring (expansion) of this term from the concept of economic system result formation (production function) to the concept of its adaptation. Some specific elasticity functions could be obtained with a correspondent reexpression from known typical production functions [20].

Indeed to be determined let $p=\pi\left(S_{1}, S_{2}, \ldots, S_{N}\right)$ is a continuous scalar production function; $\pi(0)=0$ and $\pi\left(S_{1}^{0}, S_{2}^{0}, \ldots, S_{N}^{0}\right)=p^{0}$ is a condition of initial balanced state of a program.

Lets assume we need to find elasticity function $\Theta=$ $f\left(\Delta_{1}, \Delta_{2}, \ldots, \Delta_{N}\right)$,

where $\Theta=\left(P^{0}-\pi\left(S_{1}, S_{2}, \ldots, S_{N}\right)\right) / P^{0}, \Delta_{j}=\left(S_{j}^{0}-S_{j}\right) / S_{j}^{0}$.

Expressing $S_{j}$ through $\Delta_{j}$ and substituting this expression instead of $S_{j}$ we have:

$$
\begin{aligned}
& f(\Delta)=\theta=1-\frac{1}{p_{0}} \pi\left[S_{1}^{0} \cdot\left(1-\Delta_{1}\right), S_{2}^{0} \cdot\left(1-\Delta_{2}\right), \ldots\right. \\
& \left.\ldots S_{N}^{0} \cdot\left(1-\Delta_{N}\right)\right] .
\end{aligned}
$$

From the perspective of abovementioned let's consider as examples some elasticity functions obtained by means of (1) from known typical production functions.

1. Linear production function:

$$
P=Y=a_{1} S_{1}+a_{2} S_{2}+\ldots+a_{N} S_{N}
$$

Then:

- cybernetic control principles - emergence, necessary variety, external addition, feedback, systematicity, hierarchy etc. - are well known and are used to plan and manage systems.

\section{RESEARCH METHODS}

Assessment of economic sustainability of a complex system is possible basing on development of theory of elasticity. Elasticity is interpreted as ability of an economic system to neutralize perturbations suffering herewith some deformations (losses) in achievement of target indicators but avoiding however their complete non-achievement (it is clear that flexibility and maneuverability act like a sort of internal 
It is easy to figure out condition of neutralization of

$f(\Delta)=1-\frac{1}{Y_{0}}\left(a_{1} S_{1}^{0}\left(1-\Delta_{1}\right)+\right.$

$\left.+a_{2} S_{2}^{0}\left(1-\Delta_{2}\right)+\ldots+a_{N} S_{N}^{0}\left(1-\Delta_{N}\right)\right)=$

$=1-\frac{1}{Y_{0}}\left(a_{1} S_{1}^{0}+a_{2} S_{2}^{0}+\ldots+a_{N} S_{N}^{0}-a_{1} S_{1}^{0} \Delta_{1}-\right.$

$\left.-a_{2} S_{2}^{0} \Delta_{2}-\ldots-a_{N} S_{N}^{0} \Delta_{N}\right)=1-\frac{1}{Y_{0}}\left(Y_{0}-a_{1} S_{1}^{0} \Delta_{1}\right.$

$\left.a_{2} S_{2}^{0} \Delta_{2}-\ldots-a_{N} S_{N}^{0} \Delta_{N}\right)=1-1+\frac{a_{1} S_{1}^{0}}{Y_{0}} \Delta_{1}+$

$+\frac{a_{2} S_{2}^{0}}{Y_{0}} \Delta_{2}+\ldots+\frac{a_{N} S_{N}^{0}}{Y_{0}} \Delta_{N}=\frac{a_{1} S_{1}^{0}}{Y_{0}} \Delta_{1}+$

$+\frac{a_{2} S_{2}^{0}}{Y_{0}} \Delta_{2}+\ldots+\frac{a_{N} S_{N}^{0}}{Y_{0}} \Delta_{N}$

Elasticity function is not invariant to $\mathrm{P}_{0}\left(\mathrm{Y}_{0}\right)$.

2. Production function with mutually complementary factors:

$$
\begin{aligned}
& p=\min _{1 \leq j \leq N}\left(a_{j} \cdot S_{j}\right) \cdot a_{j} \cdot S_{j}^{0}=P_{0} ; \forall_{j}=1, \ldots, N \\
& f(\Delta)=1-\frac{1}{p_{0}} \cdot \min _{i}\left[a_{j} \cdot S_{j}^{0} \cdot\left(1-\Delta_{j}\right)\right]= \\
& =1-\min _{i} \cdot\left(1-\Delta_{j}\right)=\max _{j} \Delta_{j} .
\end{aligned}
$$

It is visible from the construct $f(\Delta)$ that in the presence of such elasticity function elimination (neutralization, extinguishing) is absent in relation to any of input perturbations.

This example gives an idea to define in the correspondent way compensating ability of an economic object. Let us say that this object under a given development program (performance) possess compensating ability in $k$ th target indicator in relation to realization $\delta$ of vector $\Delta$, when:

$$
f^{k}(\delta)<\max _{j} \delta_{j}
$$

3. Power production function (function with mutually complementary factors):

$$
\begin{aligned}
& P=a \cdot \prod_{j=1}^{N} S_{j}^{\alpha_{j}} \\
& f(\Delta)=1-\frac{1}{P_{0}} \cdot a \cdot \prod_{j=1}^{N} S_{j}^{0^{\alpha_{j}}} \cdot\left(1-\Delta_{j}\right)^{\alpha_{j}}= \\
& =1-\prod_{j=1}^{N}\left(1-\Delta_{j}\right)^{\alpha_{j}} .
\end{aligned}
$$

perturbations vector $\delta$.

Let $\delta_{j_{0}}=\max _{j} \delta_{j}$. Taking the logarithm of inequation

$$
1-\prod_{j=1}^{N}\left(1-\delta_{j}\right)^{\alpha_{j}}<\delta_{j_{0}}\left(0<\delta_{j}<1, \forall_{j}\right)
$$

We have:

$$
\sum_{j} \alpha_{j} \cdot\left[-\lg \left(1-\delta_{j}\right)\right]<-\lg \left(1-\delta_{j_{0}}\right)
$$

As the right side of this formula is not less that any of multipliers in the brackets under the summation symbol, it would be true for all $\delta$, if $\sum_{j} \alpha_{j}<1\left(\alpha_{j}>0\right)$; when $\sum_{j} \alpha_{j}=$ 1 inequality is also present excluding the case with $\delta_{1}=\delta_{2}=$ $\ldots=\delta_{N}$; when $\sum_{j} \alpha_{j}>1$ its trueness depends on interrelation between components of $\delta$.

Let us note considered above elasticity (3) and (5) functions are invariant relative to volume of program setting $P_{0}$.

\section{RESULTS}

Let's illustrate application of elasticity functions to two econometric models in order to evaluate consequences of resource perturbations.

1. Econometric model of long-term type is based on the classic Cobb-Douglas production function and is written as [21]:

$$
P=Y=a K^{0.48} L^{0.39} G^{0.05} I^{0.04} M^{-0.05} D^{0.02},
$$

where $\mathrm{Y}$ is gross domestic product (GDP),

$$
\begin{aligned}
& \text { K - fixed capital, } \\
& \text { L - employment, } \\
& \text { G - products trade flow, } \\
& \text { I - innovations, } \\
& \text { M - migration flows, } \\
& \text { D - data flows. }
\end{aligned}
$$

Elasticity function (type (5)) $f(\Delta)=1-\prod_{j=1}^{N}\left(1-\Delta_{j}\right)^{\alpha_{j}}$; possible perturbation (deviations) in arguments-factors would cause correspondent deviations of target indicator GDP (Y).

Therefore when $\Delta_{K}=0.20, f\left(\Delta_{K}\right)=1-(1-$ $0.20)^{0.48}=1-0.898 \approx 0.10$;

when $\Delta_{G}=0.20, f\left(\Delta_{G}\right)=1-(1-0.20)^{0.05}=1-$ $0.988 \approx 0.011$

when $\Delta_{M}=0.20, f\left(\Delta_{M}\right)=1-(1-0.20)^{-0.05}=1-$ $1.0112 \approx-0.011$ etc.

Evaluating calculations for the resource's volumes decreased by $20 \%$ are shown in the Table I. 
To describe formation of innovative products volume let's turn to regression analysis methods. In general multiple regression equation looks like:

$$
Y=X \Theta+\mathrm{E}
$$
positively on GDP, namely, decrease of migration flow by $20 \%$ leads to GDP growth by $1.1 \%$. The strongest GDP decrease (by 10\%) could happen in case of basic capital decrease by $20 \%$.

TABLE I. GDP CHANGE AS A RESPONSE OF RESULTING INDICATOR TO RESOURCE PERTURBATION INVOLVING DECREASE OF RESOURCES UTILIZATION IN A NON-LINEAR PRODUCTION FUNCTION

\begin{tabular}{|l|l|l|}
\hline No. & $\begin{array}{c}\text { Resource perturbation (underfunding / } \\
\text { decrease of volume of resource factor } \\
\text { variable) }\end{array}$ & $\begin{array}{c}\text { Response of resulting } \\
\text { indicator of production } \\
\text { function - GDP change }\end{array}$ \\
\hline 1 & Underfunding in capital (K) $-20 \%$ & Decrease of GDP $-10.0 \%$ \\
\hline 2 & $\begin{array}{l}\text { Decrease of labor force in economy (L) }- \\
20 \%\end{array}$ & Decrease of GDP $-8.33 \%$ \\
\hline 3 & Decrease of trade volume (G) $-20 \%$ & Decrease of GDP $-1.10 \%$ \\
\hline 4 & Decrease of innovations level (I) $-20 \%$ & Decrease of GDP $-0.89 \%$ \\
\hline 5 & Decrease of migration flow (M) $-20 \%$ & Increase of GDP $-1.10 \%$ \\
\hline 6 & Decrease of date flow (D) $-20 \%$ & Decrease of GDP $-0.45 \%$ \\
\hline
\end{tabular}

2. Econometric model of innovative products output in Russia [22].

Based on Russian statistics agency date 12 factors determining innovative products output in Russia were detached:

$\mathrm{x} 1$ - share of personnel engaged in scientific research and development, per 1000 inhabitants, \%;

x 2 - share of researcher having scientific degree, per 1000 inhabitants, \%;

x3 - internal costs on scientific research and development, mln rubles;

$\mathrm{x} 4$ - patents granted, pcs;

$\mathrm{x} 5$ - expenditures on technological innovations, mln rubles;

x6 - advanced production technologies used, pcs;

$\mathrm{x} 7$ - number of organizations engaged on scientific research and development, pcs; $\%$

x 8 - share of post-graduate students per 1000 inhabitants,

x9 - innovative activity of organizations, \%;

x10 - turnover of medium organizations, bln rubles;

x11 - average income per capita, rubles;

$\mathrm{x} 12$ - investments in basic capital, mln rubles.

In order to make different-scale indicators comparable the input data were normalized according to formula:

$$
\tilde{x}=(x-\bar{x}) / \sigma_{x},
$$

where $\sigma_{x}-$ mean square deviation. where $Y$ is a vector of response values; $X$ is a matrix of independent variables values for $\mathrm{N}$ experiments; $\Theta$ is a vector of unknown parameters of a model; $E$ is a vector of random errors.

Using the least square method allowed to obtain estimation of regression equation for the model (7):

$$
\begin{aligned}
& Y=0.08 x_{1}-0.23 x_{2}-0.39 x_{3}+0.36 x_{4}+ \\
& 0.70 x_{5}+0.16 x_{6}+0.37 x_{7}+0.01 x_{8}- \\
& -0.08 x_{9}-0.11 x_{10}+0.29 x_{11}-0.30 x_{12}
\end{aligned}
$$

Determination coefficient and Fishers ratio are significant for this model, i.e. the model is suitable for description of studied phenomena. In order to range the factors by their influence on volumes of innovative products in Russia the method 'Least Absolute Shrinkage and Selection Operator' (LASSO) suggested by R. Tibshirani was used. It turned out the strongest influence on response is shown by the 5th, 6th and 11 th factors.

The formula (5) can be used to construct the corresponding elasticity function. 144 .

Let's suggest that $x_{5}{ }^{0}=100, x_{6}{ }^{0}=100$ and $x_{11}{ }^{0}=200$; then $\mathrm{Y}_{0}=$

When $\Delta_{5}=0.10(10 \%), f\left(\Delta_{5}\right)=0.7 * 100 * 0.10 / 144=$ 0.049 (almost $5 \%$ ).

When $\Delta_{6}=10 \%, f\left(\Delta_{6}\right)=1.11 \%$.

When $\Delta_{11}=10 \%, f\left(\Delta_{11}\right)=4 \%$.

It follows thence that in the economy of Russia the most desirable is to increase in the first turn expenditures on technologic innovations of organizations, as when they grow by $10 \%$ the volume of innovative products in economy would increase by almost $5 \%$.

\section{DISCUSSION}

In real practice for many random perturbations the most typical distributions are those which decrease quite steeply when both positive and negative deviation values increase. It looks quite natural as planned variants which are combined with high probabilities to large expected perturbations are most often thrown away a priori. Such a character of perturbations distributions may also serve as an indirect proof of existence of mechanical compensation of these perturbations in economy.

Also let us note that a formal relationship between a production function and an elasticity function should not conceal their principal difference, implying that they represent different aspects of the program of development or 
functioning of an economic system: the former simulates the mechanism of program tasks forming while the latter simulates the mechanism of their stabilization or, more precisely and in a wider interpretation, the mechanism of adaptation built-in in the program. The latter manifests only when the assumed conditions of program implementation are violated and thus generally speaking, when the conditions of generating the production function of the chosen program version are violated.

So far mutual substitutability of production factors is one of the characteristics of production process, process of results obtaining and at the same time a prerequisite of maneuvering. However, reserves in their principal meaning are an attribute of only an adaptive aspect of a program because the production function always describes production possibility limits.

Application of the elasticity model gives an estimation of the target indicator deviations in various changes of external environment comparing to the predicted values. Calculation results are used for scientific substantiation of improvement in the project management mechanism aimed at increasing its efficiency.

\section{CONCLUSION}

Thus, the essence of economic sustainability is defined through such mutually related characteristics as managing ability and adaptability, and the latter splits into economic reliability (risk sustainability) and cumulative efficiency (performance). At the same time the above characteristics and economic sustainability itself are formed due to a whole set of factors all before due to the flexibility and maneuverability, functioning of certain institutions, application of cybernetic principles of efficient management. An approach to evaluation of social and economic system sustainability basing on the theory of elasticity is proposed and tested.

Application of the elasticity function gives an estimation of the target indicator deviations in various changes of external environment comparing to the predicted values. Hereafter sustainability indicators can be calculated for various levels and types of perturbations. Calculation results are used for scientific substantiation of improvement in the project management mechanism aimed at increasing its economic reliability and efficiency and hence adaptability and sustainability of the respective economic system. Proposed approach could be applied both at the stage of elaboration of programs and projects of economic systems development (including regional systems) and at the stage of implementation in the process of revealing possible resource limitations and correction of targets and ways of their achievement.

\section{REFERENCES}

[1] M. Vinogradov, Mathematical Encyclopedia, vol. 5, 1985.

[2] A. Voronov, Automatic control theory, part II, 1977.

[3] M.A. Yülek, Industrial Policy and Sustainable Growth, 2018.

[4] O.G. Bodrov, V.A. Mal'gin, V.G. Timiryasov, Economic Freedom and Stability of Enterprises, 2000.
[5] "Prosperity without growth? The transition to a sustainable economy," Sustainable Development Commission. London, Edinburgh, Cardiff, Belfast, 2009. [Electronic resource]. URL: http://www.sdcommission.org.uk/data/files/publications/prosperity_without_growth_r eport.pdf (accessed on 1 June 2019).

[6] United Nations, Transforming our world: the 2030 Agenda for Sustainable Development, 2015. [Electronic resource]. URL: https://sustainabledevelopment.un.org/post2015/transformingourworld (accessed on 1 June 2019).

[7] R. Gajbiye, "A sustainable redistribution model based on economicenvironmental equilibrium: a global business perspective," Int. J. Innovation and Sustainable Development, vol. 12(4), 2018, pp. 421-445.

[8] R. Kumar, S.K. Yadav, S. Verma, "Intellectual property rights protection and foreign direct investment: a study of BRICS countries," World Rev. of Entrepreneurship, Management and Sustainable Development, vol. 14(6), 2018, pp. 694-704.

[9] N.M.P. Bocken, S.W. Short, P. Rana, S. Evans, "A literature and practice review to develop sustainable business model archetypes," J. Clean. Prod., vol. 65, 2014, pp. 42-56.

[10] V.V. Krivorotov, A.V. Kalina, Z.S. Belyaeva, S.Y. Erypalov, "Optimisation model for industrial complex competitiveness: a path to sustainable innovation process," World Rev. of Entrepreneurship, Management and Sustainable Development, vol. 12(2-3), 2016,254-269.

[11] B.M.H. Subrahmanya, "Role of the triple helix in the ecosystems for tech start-ups in India: a gap analysis," Global Business and Economics Review, vol. 21(3-4), 2019, pp. 450-473.

[12] P.C. Kesavan, "Shaping science as the prime mover of sustainable agriculture for food and nutrition security in an era of environmental degradation and climate change," Curr. Sci., vol. 109(3), 2015, 488-501.

[13] A. Behl, A. Pal, "Sustainability of environmentally sound technologies using interpretive structural modelling," Int. J. Innovation and Sustainable Development, vol. 13(1), 2019, pp. 1-19.

[14] World Economic Forum, Digital Transformation Initiative, in collaboration with Accenture, Executive summary, 2017. [Electronic resource]. https://www.accenture.com/t20170411T120304Z_w_/usen/_acnmedia/Accenture/Conversion-Assets/WEF/PDF/Accenture-DTIexecutive-summary.pdf (accessed on 20 June 2019).

[15] K.A. Bannova, N.E. Aktaev, "Mathematical modelling of optimal tax trajectory within the framework of Cobb-Douglas model," Applied Economics Letters, 2019, pp. 1-7, DOI: 10.1080/13504851.2019.1688240.

[16] H. de La Fuente-Mella, A.M. Vallina-Hernandez, R. Fuentes-Solis, "Stochastic analysis of the economic growth of OECD countries," Economic Research-Ekonomska Istraživanja, 2019, pp. 1-14, DOI:10.1080/1331677x.2019.1685397.

[17] Y.R. Limam, S.M. Miller, G. Garzarelli, "Output Growth Decomposition in the Presence of Input Quality Effects: A Stochastic Frontier Approach," German Economic Review, vol. 20(4), 2019, pp. 383-409, DOI: 10.1111/geer.12147.

[18] A. Heshmati, M. Rashidghalam, "Estimation of technical change and TFP growth based on observable technology shifters", Journal of Productivity Analysis, 2019,1-16, DOI: 10.1007/s11123-019-00558-5.

[19] A.I. Karpovich, G.P. Litvintseva, "Essence and estimation of economic system sustainability," Springer Proceedings in Business and Economics [IECS 2018: Innovative business development - a global perspective: 25 intern. economic conf., Romania, Sibiu], 2018, pp. 99-110, DOI: 10/1007/978-3-030-01878-8_9.

[20] G. Renshaw, Maths for Economics, 2005.

[21] Digital globalization: The new era of global flows, Report McKinsey Global Institute, 2016. [Electronic resource]. URL: https://www.mckinsey.com/business-functions/digital-mckinsey/ourinsights/digital-globalization-the-new-era-of-global-flows (accessed on 1 June 2019).

[22] G.P. Litvintseva, V.Yu. Shchekoldin, E.A. Schits, "Forecasting the results of innovative activity taking into account significant factors in the regions of Russia," Stud. Russ. Econ. Dev., vol. 28(5), 2018, 528-53 